
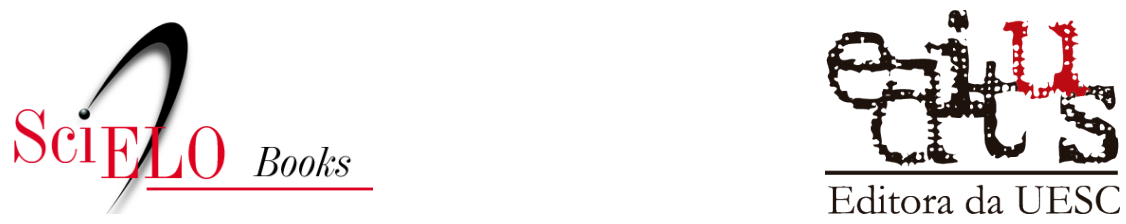

\title{
1. A você, leitora!
}

\author{
Kauan Almeida
}

\section{SciELO Books / SciELO Livros / SciELO Libros}

ALMEIDA, K. A você, leitora!. In: Ficções do ser: o entre-lugar de bichas pretas na escola [online]. Ilhéus, BA: Editus, 2020, pp. 21-36. Transfluência series. ISBN: 978-65-86213-15-7. https://doi.org/10.7476/9786586213300.0002.

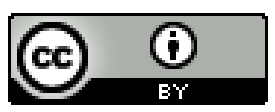

All the contents of this work, except where otherwise noted, is licensed under a Creative Commons Attribution 4.0 International license.

Todo o conteúdo deste trabalho, exceto quando houver ressalva, é publicado sob a licença Creative Commons Atribição 4.0.

Todo el contenido de esta obra, excepto donde se indique lo contrario, está bajo licencia de la licencia Creative Commons Reconocimento 4.0. 


\section{1}

\section{A você, leitora!}

Quando, em agosto de 2017, recebi a notícia da minha aprovação no Mestrado Profissional ${ }^{1}$ em Ensino e Relações Étnico-Raciais da Universidade Federal do Sul da Bahia, por um momento fiquei atônito, afinal, seria um acontecimento único e importante tanto na minha vida quanto na da minha família, pois, diferente de toda a trajetória da minha família, eu teria a oportunidade de ser alçado à titulação de mestre, mesmo não sabendo muito bem o significado disso.

Eu já vinha de um percurso que me inseriu nos movimentos negros e LGBTs, o que fez com que eu tivesse contato com literaturas mais específicas e a consciência do meu corpo em alguns espaços, principalmente no que se refere às questões raciais. Foi este mesmo percurso militante que me lançou a reflexões sobre o enclausuramento do meu corpo às marcas corpóreas da escravidão, assim como a dupla consciência, sobre a qual teorizaram Du Bois e Paul Gilroy, de encontrar-me seccionado entre a raça e todas as outras interpelações que transcendem o campo racial, como é o caso da sexualidade.
1. O presente texto foi utilizado como trabalho de conclusão do Mestrado Profissional em Relações ÉtnicoRaciais da Universidade Federal do Sul da Bahia. Por isto, optouse por deixar esse rastro informativo para o conhecimento da leitora. 
Se a brasilidade evoca uma mistura festiva das três raças (branca, negra e indígena) formando um contínuo miscigenado, não fazia sentido autodeclarar-se negro no interior de uma nação onde a sua cor não é lida enquanto mácula. Mas você sabe que isso é mentira, não é? Porém, com 6 anos, como eu iria saber?! Adotei, assim como muitos, uma forma-mulata que é expressa no negro-do-sorriso-bonito que adora o seu país tropical e abençoado por Deus, mas que, assim como muitas outras negras, vive encapsulado em favelas da capital paulistana.

E aqui quero começar a conversar diretamente com você. Você que lerá este texto e que de alguma forma terá acesso a mim e às minhas vertigens. Embora pareça que eu esteja a representar algum grupo social, eu não estou. Produzo só a mim mesmo, não por egoísmo, mas por impossibilidade teórica de estender o caos e transformar força em forma.

As pessoas, não sei se você também, têm muita curiosidade em saber como são as vidas das pessoas negras, como são as vidas das pessoas homossexuais, no limite, como são as vidas daquelas que se diferem da forma branca, cis-heterossexual, masculina, cristã e burguesa. Percebo que soa quase como um fetiche para elas. Em muitas mesas que participo e convites que recebo, há uma nota de rodapé invisível em que diz "divida com o mundo as dores de ser bicha e preta. Fale sobre suas vivências, sobre as violências sofridas".

Sempre que percebo esta nota de rodapé, sinto uma imensa tristeza, pois, normalmente são pessoas inteligentes que querem saber qual a experiência de um corpo negro 
e bicha. Estas perguntas e convites carregam um forte teor narcísico e nos querem como macacos, para alegrar a plateia, ou como dramáticos, para fazê-la chorar. Ao final, uma interlocutora se dirige a todas e diz "precisamos respeitar negros, mulheres, indígenas e LGBT's, pois são humanas como nós". Mas, ao que me parece, esta humanidade só nos é ofertada momentaneamente enquanto sangramos falando do "nosso" difícil passado de luta e sofrimento.

No limite, não é respeito, mas sim piedade. Daí que algumas sempre nos dirigem as falas em tom caridoso. É triste, você não acha? Como posso falar sobre escravidão ou significado de privilégio branco, quando a minha interlocutora encarna todas as heranças de pilhagem e violência e parece não se dar conta disso? Ou, quando acontece de se sentir culpada e assumir publicamente o seu privilégio, me pergunto, às vezes, o que querem que façamos com isso? As raças, os gêneros e as sexualidades são produzidas ainda como naturais, logo, suas descrições acompanham sentidos que tentam a todo instante nos fixar. Mas, as negras e a raça, assim como as homossexualidades e a sexualidade, nunca foram elementos fixos.

Mas a violência que constitui o racismo e a homofobia é consequência inalienável desta necessidade de identificar, de produzir o sujeito negro, assim como o homossexual, no interior das mesmas arenas hierárquicas de colonização e pilhagem. Essas identificações são estratos hierárquicos que conferem inteligibilidade à vida social a partir do reconhecimento. No Brasil, por exemplo, são estas crenças nos estratos hierarquizados que tentam definir quem pode cagar em um shopping e quem não pode 
2. Disponível em: http://sportv. globo.com/site/ programas/ta-na-area/ noticia/2017/07/ richarlyson-sobrehomofobia-e-vazio-taopequeno-para-aquiloque-eu-sou.html
(SCHUCMAN, 2012), assim como quem é afeminado de-

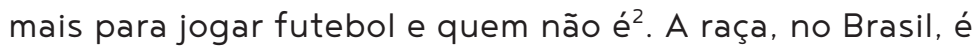
menos uma questão de árvore genética do que uma questão privilegiada à brancura (SOUZA, 1983) - brancura que ultrapassa os significados do ser branco enquanto indivíduo e se estabelece mais como uma rede discursiva de poder-saber.

E é esta crença na brancura, coisa que você já deva ter percebido, que faz com que pessoas, para além do cabelo, nariz, cor de pele, sejam levadas a acreditar na ficção da branquitude, assim como outras são levadas à da negritude, assim como outras são levadas à da heterossexualidade, etc. Mas, a diferença aqui reside nos significados atribuídos a cada uma dessas construções modernas. Elevadas à representação, caem em uma espiral de teias discursivas presas a aparatos estereotipados. A brancura, por exemplo, nunca esteve relacionada negativamente à pilhagem, a violências, guetificações e encarceramento em massa; quando sujeitos brancos experimentam essas condições, é, pois, a extensão daquilo que Mbembe (2018) teorizou como o Devir-Negro do mundo.

Mas, o que leva os sujeitos a se enxergarem como brancos ou negros? Eu, de fato, não tenho respostas a esta questão, mas - concordo com Ta-Nehisi Coates (2015) que não foram atividades como "degustações de vinhos e sorvetes" - sabemos que a brancura se alçou a tal posição através das violências, dos mecanismos extrativistas de vida e terra, pelo açoite às diferenças e a negação do outro enquanto governantes de seus corpos.

Mas, como muitas de nós sabemos, o Brasil nunca pensou na condição do homem e da mulher escravizados 
no pós-abolição; aliás, o Brasil é excepcional em apagar as memórias da sua própria violência. Caso você duvide, peço rapidamente que pare esta leitura e faça uma pesquisa no Google sobre em que transformaram os pavilhões do Carandiru, onde 111 homens foram mortos. E sim, é mais fácil viver com a virtuosidade da ignorância e brincar nos jardins do Carandiru do que ter que olhar para aquele prédio e recordar da força genocida do nosso país tropical, que trucida corpos negros por "engano" ou por esporte.

Porém, acredito, talvez esteja enganado, que muitas de nós não participamos ativamente dos luxos que produzimos e isto pode nos irromper em um grande ódio contra eles. E novamente habitamos as fronteiras ficcionais polarizadas que dividem eles de nós, mas é justamente na fronteira que vivemos, ou, como falo por mim, que vivo. Recentemente, enquanto escrevia o que viria a ser a primeira seção da dissertação, fui interrompido, pois, no bairro onde moro, dois homens negros foram mortos pela polícia ${ }^{3}$ e duas outras pessoas ficaram feridas. Quase que instantaneamente recebi as fotos pelo WhatsApp, assim como áudios dos tiros.

Um dia depois, um outro homem negro foi morto ${ }^{4}$, em plena luz do dia, enquanto dirigia uma lotação; as notícias diziam que ele teria sido confundido com um traficante. Quando saí da periferia de São Paulo para a Bahia, pensei que veria menos casos de mortes, mas me enganei. Eu aprendi muito cedo que a polícia tem autoridade para destruir corpos negros, seja por engano ou por "proteção aos cidadãos de bem". Eu vi a polícia atirar em amigos meus em frente à escola, vi policiais passando com suas viaturas e atirando em sujeitos negros, fugi de policiais que atiravam loucamente enquanto brincávamos próximos à valeta
3. Disponível em: https://radar64. com/noticia/ identificado-segundomorto-em-tiroteio-nocambolo_39758.html

4. Disponível em: https://radar64.com/ noticia/motorista-delotacao-e-morto-amigofica-ferido_39784.html 
da rua 3, na favela do Pantanal, no Itaim Paulista, e tive policiais apontando suas armas em direção à minha cabeça, em revistas noturnas e em manifestações por direitos básicos, como o de estudar.

Assim, aprendi à força como um corpo negro deve se comportar em algumas situações, é algo da ordem de saber manter a medida certa, caso deslize para mais ou menos, qualquer ação é perigosa: uma reação extrema a uma abordagem, perigo latente; sozinho em ruas escuras, perigo latente; marcar de encontrar amigas/os na esquina, perigo latente; estar com um amigo branco no ponto de ônibus à noite, perigo latente. E o mais aterrorizador é que estas experiências não estão distantes daquelas relatadas por outros corpos negros, pobres e jovens. Dessa forma, as dicas de como "escapar" ao potencial de destruição destas máquinas públicas de segurança à brancura são passadas quase como uma receita ancestral: leve seus documentos, não reaja, responda somente o necessário.

Mais tarde, percebi que muitos policiais, para não dizer todos que atuavam no bairro onde eu morava, eram "irmãos", isto é, outros homens negros. Mas, se você está seduzido à narrativa do poder, a coisa é outra e o buraco não é mais embaixo, é em locais letais. Não sei se você tem ideia do que é esta experiência, mas, sinceramente, espero que não; ela talvez seja um dos contatos mais dolorosos com a cicatriz coIonial. Ela marca nossos corpos com toda a herança escravocrata. A experiência do racismo é tamanha que possivelmente nos faça sangrar sorrindo, é da ordem do visceral, pois sempre culmina no corpo, ainda que você só veja gráficos e tabelas, números e estatísticas, ciências humanas e artes. 
Quando Foucault (2013) escreveu que estava condenado a viver no próprio corpo, ele não tinha ideia do quanto iria me afetar essa sua leitura, assim como quando Fanon (2008, p. 126) escreveu:

O preto é um brinquedo nas mãos do branco; então, para romper este círculo infernal, ele explode. Impossível ir ao cinema sem me encontrar. Espero por mim. No intervalo, antes do filme, espero por mim. Aqueles que estão diante de mim me olham, me espionam, me esperam.

Eu sei, Fanon e Foucault não escreveram para mim, mas gosto de pensar que sim, assim crio uma afinidade poética com a escrita. Durante a minha vida, tenho lutado para encontrar a melhor maneira de viver dentro de um corpo negro - ainda não comecei a falar sobre a sexualidade.

Há algum tempo decidi me desfazer de um vocabulário para falar sobre raças, gêneros e sexualidades ${ }^{5}$. Rejeitar um vocabulário é uma quebra no meu percurso formativo como intelectual, pois passei a rejeitar simplificações que, não raramente, caem em essencialismos ou em discursos revestidos de uma aura cientificada que nos faz jogar o jogo do racismo científico e que nos coloca na ideia moderna sobre corpos negros. Isto, para muitos colegas de militância, soou e ainda soa como um embranquecimento, uma ocidentalização do pensamento, mas, acredito eu, que seja uma fuga às fórmulas mágicas que prometem a emancipação.

A minha atual ideia de liberdade gira em torno de viver livremente dentro do meu corpo negro e bicha, ainda que eu não tenha uma linguagem adequada para expressar
5. Refiro-me a um vocabulário expresso em uma ontologia da representação. 
como. Durante minha infância, a linguagem preponderante na minha comunidade era a do medo. Fomos forjados no e pelo medo a ponto de uma descorporização de alguns. O medo era uma expressão também. Garotos com suas posturas eretas pelo medo; calças baixas deixando à mostra suas cuecas por medo; bonés com suas abas retas de medo; um jeito meio agressivo de mascar os chicletes do medo; uma forma de impor o medo a outros por simplesmente sentirmos medo.

Tudo isso formava um aglomerado de signos e seus sentidos que, ao inspirarem medo ao outro, causava uma sensação de poder local. Era esta impressão de poder que fazia com que alguns garotos pudessem se sobressair a outros, o medo era, no final, uma grande máscara para esconder como nossos rostos continham marcas coloniais. As máscaras tinham, também, seu contraefeito; ao utilizá-las estaríamos suscetíveis à violência, às armas de fogo que outros meninos levavam para a escola e às drogas que eram vendidas por sujeitos de toucas escuras que ficavam encostados nos muros, mas sem utilizar máscaras. Possivelmente, nossa nudez seria castigada pelo efeito das políticas de segurança pública.

A máscara racial utilizada por homens negros é muitas vezes revestida por um componente da masculinidade cis heterossexual que emula comportamentos patriarcais de senhores brancos contra mulheres, na vasta maioria negras, e qualquer dissidência sexual ou corpos desobedientes aos gêneros. Estes homens são educados a partir da pedagogia da rua. E aqui abro um espaço para dizer como 
é difícil para mim refletir sobre a violência e, ainda mais, sobre aqueles que me violentam, mas continuemos. A pedagogia da rua é a educação em força - não em forma -, nos mais distintos lugares. É a empiria do aprendizado.

É na rua que aprendemos que as mortes de nossos amigos não são casos de injustiça, mas, dolorosamente, é o cumprimento da lei da brancura que exige segurança. Na rua também aprendemos a confrontar o mito da irmandade e outros mitos negros que são tão belos quanto irreais. A experiência da rua faz com que cada acontecimento seja um risco, é viver o abismo: jovens negras grávidas, filhos que crescem sem a figura paterna, saltar sacos pretos com corpos negros para ir à escola e ver amigos de infância matarem uns aos outros em nome da lei da masculinidade.

Contudo, a experiência mais avassaladora, no meu caso, foi a de escapar de jovens que aprenderam a canalizar a linguagem do medo em raiva. Esta aprendizagem é a que seduz muitos homens brancos e negros ao poder, a ponto de um garoto de 13 anos, ao se sentir humilhado após uma partida de videogame, ir à sua casa, pegar uma arma e dar três tiros nas costas de um de seus colegas. $O$ atirador se chamava Willian, estudava com meu irmão, a vítima era apelidada como Galego.

Estes homens e meninos que aprenderam a potência de seus corpos se divertiam às custas de meninos como eu: viados; e, ao mesmo tempo, me ensinaram que, se eu quisesse sobreviver, teria que aprender o ato do disfarce, teria que minimamente emular aquilo que eles faziam com maestria tamanha, a ponto de terem seus nomes cravados 
nos muros com mensagens de saudade após suas mortes. Uma bicha deveria aprender seu lugar. Assim, memorizei horários e locais dos bairros em que poderia passar. Caso fosse surpreendido por um ou outro, eu deveria enfiar minhas mãos nos bolsos e acenar com a cabeça "iaê"; qualquer suspeita sobre a minha sexualidade era perigosa.

Depois de um tempo, a gente aprende até mesmo o cheiro e o sabor. Se eu esquecesse, como algumas vezes aconteceu, teria minha punição. Garotos jovens jogavam pedras, havia a constante ameaça de apanhar no portão da escola e a experiência máxima da humilhação para uma criança que ainda não sabia direito o que era ser viado, mas, pelo jeito que ouvia outras pessoas falarem, sabia que não era uma coisa boa, pois aqueles que assim te chamam, o fazem para constrangê-lo.

A experiência da sexualidade dissidente em um corpo negro é de uma agudeza que faz qualquer palavra vacilar, qualquer gesto ser um flagelo. Medo do seu pai, da sua mãe e dos seus amigos que desconfiam, mas não têm certeza, visto que alguns se parecem mais com "homens de verdade" que outros. E isso de me saber viado me custou a maior parte do pensamento do caminho de casa à escola.

E aqui chego à escola, o meu local de pesquisa. Ta-Nehisi Coates (2015, p. 32) diz que "se você não compreender as ruas, terá desistido do seu corpo agora. Mas se não compreender as escolas, desistirá do seu corpo depois". A escola foi sempre tida, na concepção dos meus pais, como a única possibilidade de ter um futuro diferente do deles. 
Meu pai é um pedreiro que cursou até a terceira série do Ensino Fundamental, já minha mãe é uma costureira e diarista que possui o Ensino Médio incompleto.

A escola se apresenta, então, para muitas famílias negras e empobrecidas, como um local que possibilita a ascensão social, assim como produz uma distinção social entre aqueles que estão dentro e fora. Minha mãe sempre exigiu um grau de excelência nas notas tanto minhas quanto nas do meu irmão. Era uma equação muito simples: "nós não tivemos estas oportunidades, vocês têm, então não vamos deixar vocês desistirem". A não desistência da escola nos custou dores, fomes e bicos como catadores de latinha, cobre e papelão nas horas vagas, para ajudar na compra de materiais escolares e outras coisas.

O que eu não imaginava é que, no intercurso dos meus anos na escola, eu constituiria um terceiro olho, como um elemento de proteção às investidas coloniais, um terceiro olho que produzia processos de desidentificações com os quais eu questionava muitas das coisas que me eram passadas. Nas escolas em que passei, construí grandes laços de amizades. Pensando agora, foram os melhores e os piores anos da minha vida, talvez, ambos ao mesmo tempo.

Ao olhar para o passado, percebo redes de subalternização, de submissão e de produção de uma miséria racial e sexual que acontecia em muitos espaços da escola, mas, também, as contestações e subversões que produzíamos. Foi na escola que percebi como eu parecia mais forte, alegre e, paradoxalmente, mais vulnerável ao lado de amigos 
gays. Tínhamos fortes laços e, ainda que não nos identificássemos publicamente como bichas, sabíamos que fluxos outros nos atravessavam, distintos de uma pretensa heterossexualidade "natural" disposta nas imagens familiares de mamãe, papai e filhinhas/os que nos incitavam a ser.

Não era questão de somente ser negro e gay, como se fosse um cálculo somatório, era outra coisa, estávamos em outra posição. Em detrimento da soma, era potência e afronte, como só fui notar muitos anos depois. Assim, a partir da escola, aquele espaço da rua que eu entendia como perigoso para mim foi vagarosamente se transformando em outra paisagem, da alegria, do encontro e da reinvenção, diferente da minha casa, que, por medo de me "assumir" para os meus pais, foi se tornando cada vez mais violenta e silenciosa. Hoje noto que, ao enxergar somente a violência das ruas, estamos criminalizando um espaço público e que a violência que nelas vemos é, talvez, uma forma de nos domesticar na intimidade violenta de alguns lares.

E eu só pude contemplar a fascinante vivacidade da rua a partir da escola. Nela, também, tive encontros alegres com professoras/es que nos lançavam para outros lugares distantes da violência e das dores. No Ensino Médio, tive uma professora de nome Carmen, que, ao notar meus trejeitos afeminados e o grupo com quem eu andava, me deu o livro Bom-Crioulo, do Adolfo Caminha. Eu sei, embora haja muitas críticas que se possa fazer sobre o livro, na época me marcou a representação de Amaro, e eu nunca havia lido nada que contasse uma história de um homem negro e gay.

Assim, aprendi a escola, apanhei bastante até que soubesse criar estratégias para viver minhas sexualidades 
nos intercursos dos seus espaços. Eu sei, estamos saturados das descrições que apontam para a escola como um lugar pouco hospitaleiro às diferenças; e confesso, não tenho a menor vontade de reproduzir estas histórias, por isso traçarei devanei(gr)os de resistências a partir daqui.

Embora a coisa de se dizer bicha e preta sempre seja lida como uma tragédia social, alvo das discriminações mais diversas, é desde este local que enuncio as possibilidades de inventar narrativas alterizadas. Recontar nossas histórias negras e dissidentes sexuais para erigir cuírlombos, conceito que tomo de empréstimo da Tatiana Nascimento (2018). Deste local que é uma paisagem em movimento, produzimos ferramentas conceituais que desmantelam o que, durante muito tempo, nas comunidades negras, se costumou chamar de "praga branca", como se a negritude fosse uma experiência que se afirmasse unicamente na heterossexualidade.

Por isso, digo a você, leitora, que embora a constituição colonial de nossas instituições esteja pronta para nos esmagar, elas nunca serão grandes o suficiente para estrangular nossa capacidade de imaginar, de criar, de produzir bonitezas para além das visualidades estanques que nos acostumaram. O banzo não é capaz de deter os fluxos das diferenças dos corpos que, lançados no oceano, nos molham os pés à praia.

Eu tive muitas dúvidas quanto à linguagem com que escrevo, tenho medo, confesso, de parecer hermético, mas, ao mesmo tempo, não preciso me justificar. Acho que escrever seja isso, me impulsionar pelas agonias e alegrias de uma grande aventura dissonante e incerta, por isso optei por uma linguagem ensaística que beira a heresia de pensar as negritudes dissidentes sexuais como rasgos que não 
explicam, mas intensificam os acontecimentos dos nossos corpos. Se a vida é vertiginosa e incerta, por que a escrita não o seria também?

Assim, este texto foi dividido em seções-paisagens, cujos movimentos se encarregam da produção de um jeito de ver a partir das (des)costuras das próprias linhas grafadas no currículo, onde se tem certo sentido de movimento, mas não necessariamente o seu ponto de chegada. Dessa forma, são paisagens constituídas pelos trânsitos e pelas cenas, onde ficções são inscritas como possibilidades de criar mundos nos currículos.

Em Pela metade: notas de um quase início, há a imersão no campo teórico-metodológico do estudo, apresentando os principais conceitos desdobrados durante as análises, assim como os fios que conduziram (des)caminhos durante os itinerários. Em "Todas nós nascemos nus e o resto é drag": devir-bicha no currículo, constituo, a partir de duas cenas, um mapa aberto das linhas produzidas pelos movimentos de corpos estudantis. Tais movimentos, que se acoplam e se rasgam, produzem agenciamentos que deslocam corpos racializados e dissidentes sexuais da lógica identitária da representação ensaiada pelo currículo. Utilizo como suporte a filosofia da diferença de Deleuze e Guattari para operar devires que possibilitam pensar as existências escolares em outras invenções. Parto do argumento da visibilidade enquanto local de ambivalência para corpos bichas. Em "Por que tu me chamas se não me conheces?": devir-negro em um currículo, desdobro os argumentos já iniciados na paisagem anterior; contudo, dessa vez investigo outras possibilidades de existência e resis- 
tência, assim como a linha de fuga como criação de locais habitáveis para corporalidades abjetas. Antes de dar prosseguimento ao que será a última seção-paisagem, cabe um esclarecimento do motivo de ter separado em seções-paisagens distintas os devires bicha e negro.

Durante o percurso no Colégio Leonilson, observei que, embora não exista hierarquia de opressão, ela incide e marca alguns corpos em diferentes dimensões e intensidades. Daí que algumas alunas negras e gays, quando entrevistadas, observavam mais as facetas de uma homofobia em detrimento do racismo, ou vice-versa. Com isso, não penso que um seja mais ou menos relevante, em critério de análise, que outro, nem sequer julgo que não possa haver uma experiência que se ensaie como um devir-bicha-preta - que foi meu primeiro impulso de escrita, a fim de singularizar tais linhas. O que fiz foi uma tentativa de manter a minha fidedignidade com os relatos, os desejos expressos pelas estudantes e com o próprio campo. Dessa forma, não desejo, assim, reafirmar o padrão descrito em que corpos racializados são tidos enquanto heterossexuais; e corpos dissidentes como brancos. Ao contrário, as existências de corpos negros e dissidentes residem em singularidades que implicam outras maneiras de ver e enunciar sobre o mundo, assim como faz esta bicha preta que vos escreve. 
Como recolher as cinzas

das fendas abertas pelos olhos que se dilatam de pânico?

Dos pulsos quebrados pelz envergadure nio cimentad. de meu corpo?

Houve um tempo em que os fluxos da vidz eram tolhidos em mim, por aquilo que me deram:

O Ódio a minha pele

o REPUDDIO ho mEU DESEJO

Grandes grades engerrujadas pelas lendas da náo bospitzUm eu e um outro que se conjundiam

lidede

No banzo tícilo do querto, quentas bichas pretas jí pensarem no peso de suz cor e nz cor da suz sexuzlidade

e aprenderam que o amor é uma música rípida demzis parz dençzar a dois ou mais?

Aliźs, quel dicionzivio negro comporta a flexio do ver. bo emer?

$23 / 06 / 18$

36 